\title{
PROBLEMAS PSIQUIÁTRICOS EM GERIATRIA
}

\author{
Marcelo Blaya*
}

Dentro da ampla faixa do que convencionalmente se chama normalidade, o processo de envelhecimento não é diferente dos processos que caracterizam as outras etapas da vida dos sêres humanos. Assim como a adolescência pode ser um período difícil para os jovens que, traumatizados em etapas anteriores de seu desenvolvimento psicossexual, atingem esta idade mal preparados para enfrentar os stress típicos desta fase, a senilidade pode ser, e é, uma fase turbulenta para os velhos que a ela chegam sem o necessário preparo ${ }^{3}$.

Os problemas relativos ao envelhecimento e às moléstias características desta fase tornaram-se mais evidentes em face do aumento da vida média prevista para a espécie humana. Os progressos da medicina e da cirurgia, nestes últimos 50 anos, burlando o princípio darwiniano da sobrevivência do mais apto, tiveram grande repercussão para a sobrevivência da espécie.

De acôrdo com os historiadores, a vida média para os nascidos no Império Romano era de 23 anos. Em 1930 a mesma cifra era de 27 anos na India e de 33 anos no México. Desconhecem-se os valores para a população brasileira. Nos Estados Unidos da América do Norte, em 1900, a vida média prevista era de 47 anos e, em 1950, êste valor para homens subira a $67 \mathrm{e}$, para mulheres, a 71 anos ${ }^{18}$. Este aumento trouxe profunda repercussão na vida dos indivíduos e dos grupos sociais. Do ponto de vista das enfermidades psiquiátricas, essas alterações podem ser apreciadas através dos seguintes dados: enquanto os hospitais mentais do Estado de Nova York admitiam, em 1930, dois pacientes de mais de 60 anos em cada 10 novas admissões, em 1956, a proporção de enfermos de mais de 60 anos subira para 5 em cada $10^{4}$.

A transformação de pessoa normal em indivíduo "caduco" é processo lento e gradual, tornando-se difícil e muitas vêzes impossível estabelecer a divisão nítida entre essas duas condições. Com o envelhecimento nota-se: 1) diminuição de interêsse em relação ao mundo exterior e, concomitantemente, aumento de interêsse introspectivo; 2) declínio da memória, mais acentuado para fatos recentes do que para antigos; 3) diminuição na ca-

* Ex-interno do Michael Reese Hospital (Chicago, Illinois); ex-fellow da Menninger School of Psychlatry (Topeka, Kansas); ex-residente em Psiquiatria do Topeka State Hospital e do Larned State Hospital; ex-psiquiatra do South Florida Hospital (Hollywood, Florida). 
pacidade de iniciativa e na velocidade de pensamento e ação; 4) maior tendência ao raciocínio e especulação mental do que à ação.

As caracteristicas acima mencionadas são biológicas e ocorrem na totalidade dos sêres da espécie humana. Em determinadas pessoas, porém, elas provocam o aparecimento de ansiedade; para combatê-la põe-se em atividade uma série de mecanismos de defesa e, de acôrdo com o grau de primitivismo dêstes, ter-se-á uma reação neurótica ou psicótica. Estabelece-se, no entanto, um círculo vicioso, pois o aparecimento da reação angustiosa agrava ainda mais o déficit intelectual e êste, por sua vez, aumenta a ansiedade e o número de mecanismos de defesa primitivos em ação. Finalmente, a decadência e o empobrecimento psíquico do paciente atingem o ponto da demência senil $3,10,20$.

Note-se, portanto, que há sempre declínio das funções intelectuais e da potencialidade. As pessoas que se acham psicologicamente preparadas para a velhice, toleram bem tais mudanças ${ }^{11}$. Entretanto, individuos que carregam consigo desajustamentos e traumas de fases anteriores do seu desenvolvimento psicossexual, estarão menos aptos a tolerar essas mudanças que se processarão sem a harmonia de um processo biológico. A chamada "segunda infância" é, realmente, a continuação da primeira e única infância do indivíduo. $O$ infantilismo permanece disfarçado durante a fase adulta e reaparece na velhice. Êste disfarce é o convencionalismo exagerado e a capaciadde do indivíduo de imitar e fazer o que o rebanho faz ${ }^{1}$.

A fase senil tem caracteristicas peculiares a cada sexo, além das básicas e comuns a ambos os sexos.

No homem, desde muito cedo, estimula-se o gôsto da competição, da produtividade, o desejo de acumular riquezas e conseguir renome e fama. Enquanto está empenhado nesta luta, defende-se razoàvelmente bem, mesmo aquêle que vem traumatizado e, por assim dizer, estigmatizado para os problemas emocionais da velhice. Dois fatos importantes concorrem para o aparecimento dos problemas mais sérios desta fase: a inatividade profissional e o climatério. Ambos precipitam o encerramento da atividade criadora do individuo e o deixam, pràticamente, à mercê do golpe final. Esse ferimento em seu narcisismo, roubando-lhe os ídolos que eram a base de sua existência, reativa a ansiedade ligada ao complexo de castração. O mecanismo de defesa mais freqüentemente utilizado é a negação, vendo-se velhos de reputação intocável, iniciar práticas exibicionistas, recorrer à pedofilia ou entrar num frenesi de atividade ${ }^{5}$, no afã de negar o declínio crescente.

$\mathrm{Na}$ mulher, a menopausa pode constituir-se no obstáculo que faz periclitar o ego desfalecente. Simultâneamente com a menopausa, o afastamento dos filhos, pelo casamento, do marido, pela viuvez, o declínio da beleza e a incapacidade de competir com as filhas, tudo constitui um stress severo. A mulher associa a menopausa ao fim de sua atividade sexual e vê, com inveja, que a do espôso é mais prolongada, pois o climatério masculino só ocorrerá 15 a 20 anos mais tarde. Este novo fator reativa a an- 
siedade ligada à inveja do pênis e constitui outro problema a considerar neste grupo.

Para analisar as causas dos problemas psiquiátricos em Geriatria deve-se definir envelhecimento e analisar as causas biológicas, psicológicas e sociológicas que parecem ser responsáveis pelas mudanças que nêle ocorrem.

O fator tempo, em relação aos processos vitais, dá o conceito de envelhecimento. Envelhecimento é, senso lato, um processo que se inicia com a concepção e termina com a morte. Do ponto de vista pragmático dêste trabalho, a velhice ou a senilidade é a fase da vida humana que decorre do fim do período adulto até a morte.

As mudanças verificadas no processo de envelhecimento parecem decorrer das seguintes alterações: 1) suprimento insuficiente de materiais nutritivos; 2) transporte defeituoso de anabólitos e catabólitos; 3) defeito de utilização de anabólitos fornecidos à célula; 4) acúmulo de catabólitos. $\mathrm{O}$ equilíbrio homeostático parece ficar comprometido com maior freqüência pelos transtornos da circulação ${ }^{14}$. Dentre as causas etiológicas mais comuns no grupo de doentes em análise, as enfermidades vasculares, especialmente a arteriosclerose, são as responsáveis pelo maior número de casos ${ }^{17}$. Note-se que se a arteriosclerose é, por um lado, um dos fatôres freqüentemente associados à produção da síndrome clínica da "arteriosclerose cerebral", por outro lado, nem todo indivíduo com arteriosclerose terá sintomas mentais, não existindo correlação entre o grau de obstrução vascular e a severidade dos sintomas ${ }^{14}$.

Entre as causas psicológicas para os problemas psiquiátricos em Geriatria deve-se mencionar, em primeiro lugar, a personalidade do individuo nos períodos anteriores. Emprega-se aqui o têrmo personalidade no sentido de inventário das aptidões e deficiências da pessoa. É óbvio que não se terá uma velhice harmoniosa se a infância, a adolescência e a maturidade houverem sido marcadas por problemas emocionais não resolvidos. Maior reserva emocional acumulada nos primeiros anos de vida, através de uma vivência sócio-familiar satisfatória, com abundância de carinho e com relações interpessoais estáveis, que se traduz, na fase adulta, por um ajustamento sintônico na escola, na comunidade e no emprêgo, constitui garantia para uma velhice tranqüila.

A diversidade de interêsses é fator importante. O operário que, durante 30 anos, executa a mesma tarefa numa fábrica não terá a satisfação do artesão que vê a obra concluída por sua mão enquanto aquêle executa apenas uma parte de um todo. Deriva dai o valor das atividades fora do trabalho, nas quais o indivíduo consegue a satisfação que lhe é negada na revolução industrial. Essa diversidade de interêsses é uma qualidade inerente ao homem. A especialização, que Fishbein conceitua como "o processo pelo qual o homem sabe cada vez mais a respeito de menos e menos, sabendo, finalmente, tudo a respeito de nada", atrofia essa multipotencialidade do indivíduo. Chegando à inatividade, quando necessita "desespecializar-se", o individuo encontra-se prêso ao hábito e aos problemas emocionais da aposentadoria 7,16 . 
O tipo de personalidade pré-mórbida desempenha papel importante na velhice. Personalidades nas quais predomina o nascisismo primário, caracterizadas pela vigência do princípio do prazer - personalidades infantis sofrem rudemente com o envelhecimento. Menção especial deve ser feita dos individuos que se caracterizam por grande rigidez de conduta e que toleram mal o declínio físico e intelectual ${ }^{13}$. A doente cuja história se relata no fim dêste trabalho apresentava uma personalidade pré-mórbida infantil, com traços de rigidez obsessivo-compulsiva. Êsses traumatismos do narcisismo parecem ser fatôres psicológicos da maior importância; sua influência dependerá, em grande parte, da atitude do grupo social em relação à velhice.

$\mathrm{Na}$ maioria das culturas primitivas, os anciãos eram respeitados como repositórios da sabedoria tribal e guardiões da tradição oral ${ }^{15}$. Este costume parece encontrar apoio em estudos modernos, os quais concluem que, à medida que a fôrça e a capacidade de iniciativa diminuem, aumentam o poder de concentração e a resistência.

As culturas gerontocráticas oferecem aos anciãos um grande apoio externo, através de tabus e práticas tradicionais que os conservam como senhores de suas casas, regedores patriarcais dos destinos dos familiares, lideres das funções religiosas dentro do lar, conselheiros dos membros do clã e alvo do respeito de todos.

Contrastando com êsse apoio que a tradição tribal oferece aos anciãos, as culturas ocidentais chegam ao ponto de não conceder, aos velhos, uma situação definida no grupo social. O centro de gravidade dos assuntos familiares cedo foge das mãos do pai para as dos filhos, cujo sucesso financeiro e profissional os torna sucessores daquele. Ao mesmo tempo que os velhos vêem ruir seu mundo profissional, familiar e social, assistem ao desmoronamento de seus corpos e faculdades mentais. As vivendas da época presente, pequenos apartamentos e casas, não prevêem a coexistência, sob o mesmo teto, de três geraçōes. O barulho das crianças irrita os velhos; a indulgência ou intransigência dêstes torna difícil a educação daqueles. A necessidade de tolerar as excentricidades dos velhos faz com que os moços suspirem aliviados quando outro familiar convida "o problema" para sua casa. Assim, a cultura originou êsses "caixeiros-viajantes", que são bem recebidos, porém, mal tolerados. Êles próprios sentem que estão atrapalhando, que "estão no caminho".

Tratamento - Ao focar a terapêutica dêste grupo de doentes, o médico deve encarar a necessidade de tratar sempre de individuos com problemas sui generis e nunca de síndromes clínicas.

Medida fundamental é a relação médico-doente, devendo o primeiro ser capaz de tolerar e aceitar a desconfiança, a hostilidade, os sentimentos de autodepreciação da parte do enfêrmo. Êste "rapport" proporciona ao doente a oportunidade de aumentar sua auto-estima desfalcada e pode ser o fator básico para conservá-lo orientado dentro da realidade. $O$ interêsse ponderado e consistente do médico é indispensável para tal fim. 
A hospitalização impōe-se como medida terapêutica sempre que o enfêrmo represente perigo para si ou para os outros. Feita em lugar e tempo apropriados é decisivá para diminuir a ansiedade e o "acting out" $\varepsilon$. Isso se deve ao apoio externo oferecido ao ego pela disciplina hospitalar e pelos cuidados e autoridade dos membros da equipe, reforçando, por sua vez, a repressão dos instintos eròticos e agressivos. $O$ internamento dêsses pacientes em instituições mentais nem sempre significa hospitalização. A falta de estímulo, de cuidado e de enfermagem adequados, a perda da identidade do indivíduo em enfermarias superlotadas, significam sérios riscos para os doentes, riscos potencialmente maiores do que a moléstia da qual estão sendo tratados.

Dentre os métodos convulsivos, apenas a electroconvulsoterapia tem utilidade. O uso da insulina é contra-indicado formalmente, por representar sério perigo de vida e por trazer pouco ou nenhum benefício. Quando predomina o quadro depressivo, o ùso da convulsão elétrica é indicado ${ }^{2}$, a despeito da idade e do estado físico. Para a avaliação do risco, um exame físico e neurológico deve anteceder o início do tratamento. O uso de substâncias curarizantes é indispensável nesses doentes. Os tratamentos devem ser espaçados, não mais do que dois por semana, a fim de evitar um estado confusional mais grave e déficit de memória concomitante.

O uso de tranqüilizadores, especialmente a promazina e o meprobamato, diminui o nível de angústia e permite "clima" melhor para a relação terapeuta-doente. Os tranqüilizadores "per se" não resolvem problemas emocionais, assim como a aspirina não cura a febre; entretanto, como parte do tratamento, podem e devem ser utilizados, com as devidas precauções.

O uso crescente da psicoterapia de grupo 12 representa inovação importante no tratamento dos problemas emocionais em Geriatria. Êsse tipo de psicoterapia caracteriza-se por ser bàsicamente de apoio, raramente interpretativa, devendo o terapeuta e o observador assumirem atitude cordial e de interêsse em relação aos problemas apresentados. Contrastando com a função do observador em outros tipos de psicoterapia de grupo, êste tem aqui um papel ativo, participando de atividades sociais ou de trabalhos manuais introduzidos para estimular os doentes ${ }^{9}$.

Exemplo dessa associação é o que ocorreu em um grupo de 8 doentes que tratamos, a maioria dêles fora de contato com a realidade, agressivos verbal e fìsicamente. As sessões bissemanais eram precedidas de uma sessão de praxiterapia, sendo a terapeuta ocupacional a observadora do grupo. Os pacientes ocupavam-se com atividades destrutivas, porém, socialmente aceitáveis, as quais proporcionavam oportunidade para descarregar impulsos hostis e agressivos. A sessão psicoterápica que se seguia era mais calma e produtiva, havendo maior interrelação e socialização dos participantes.

A psicoterapia individual tem menor uso, sendo indicada, em casos escolhidos, como tratamento de apoio, raramente explorador. As interpretações fazem-se em niveis realísticos. A transferência positiva é utilizada ao máximo, evitando-se a interpretação dos aspectos negativos. 
A praxiterapia tem lugar de destaque no tratamento dêsses doentes. O estímulo proveniente das atividades manuais, da música, das danças, dos jogos simples, das atividades sociais, criam oportunidades para relações interpessoais e oferecem fonte inesgotável para a gratificação de necessidades instintivas dos doentes, conservando-os, assim, melhor orientados dentro da realidade ${ }^{19}$.

A vitaminoterapia, a hormonoterapia, o uso de sais minerais e medicamentos diversos são úteis quando existem indicações específicas. Seu uso indiscriminado é arma de dois gumes, escapando sua crítica ao plano dêste trabalho ${ }^{17}$.

A melhora das condições do ambiente residencial é decisivo na reabilitação do enfêrmo. O médico, por meio de seus conselhos e sua orientação, auxilia os familiares no sentido de remover os fatôres que constituem motivos de irritação para o doente. Pode-se chegar ao extremo de remover o enfêrmo do lar e colocá-lo numa morada adotiva. Quando existe situação de incompatibilidade entre o paciente e seus familiares, o lar adotivo pode proporcionar ao enfêrmo condições de vida superiores, física e psicològicamente, àquelas que êle encontrava em sua própria casa ${ }^{6}$. Por outro lado, em casas de repouso bem organizadas, o enfêrmo convive com pessoas de sua geração, tem a vantagem de atividades sociais, recreativas e ocupacionais em comum, além de assistência médica e custódia contínuas.

O caso que abaixo relatamos exemplifica a terapêutica utilizada numa doente senil. Neste exempio fêz-se o que convinha à doente e as soluções encontradas levaram em consideração sua psicodinâmica. A escolha da doente, que já apresentava sintomas por espaço superior a 10 anos e apresentava uma reação psicótica por ocasião de sua hospitalização, permite dar idéia de um caso que, em muitos hospitais, é considerado irrecuperável.

Resumo da história clínica - S. é dona de casa, branca, casada, com 72 anos de idade, residente em Empória (Kansas); admitida ao Topeka State HIospital em agôsto de 1956. A paciente era a quinta de sete crianças nascidas numa familia operária de Kansas. A mãe foi descrita como mulher dominadora, rígida em suas relações com o marido e os filhos, ótima dona de casa e de elevado padrão moral e religioso. O pai fôra mineiro e falecera quando a doente tinha 6 anos de idade. Com as dificuldades financeiras criadas, a mãe dedicou-se a manter pensionistas, cabendo aos filhos as tarefas relacionadas com a manutenção da pensão. A doente frequientou a escola dos 6 aos 16 anos, concluindo o ginásio. Na escola fizera boa adaptação com colegas e professoras. Trabalhou com a mãe, que sempre a dominou, até seu casamento, aos 32 anos de idade, com um homem divorciado. Desta união nasceram 4 filhos, 3 vivos e 1 falecido. Na ocasião da hospitalização, os filhos contavam 39, 37 e 35 anos de idade, todos casados e morando fora da casa materna. A mais moça, a única mulher, residia em Empória e tinha a seu cargo a mãe doente. A filha descreve seu pai como pessoa muito religiosa, trabalhando no comércio até sofrer o terceiro "ataque do coração", quando se aposentou. Da mãe, diz que fôra sempre pessoa com aspirações à perfeição, elevado padrāo moral, boa dona de casa, compulsiva, preocupada com a ordem e limpeza do lar. Desde os primeiros anos de casada exigira cama separada do marido, sendo avessa ao ato sexual e dêle fazendo uso para obter favores do espôso, o qual a julgada frigida. 
O filho mais moço morrera em 1944, em acidente de avião. A paciente pareceu receber esta morte com calma, ficando entāo acamada durante dois dias. Quando o corpo do filho foi recebido e sepultado ela pareceu ter ficado mais aliviada. A partir de setembro de 1944 começou a receber cheques mensais de um seguro de vida deixado pelo filho, os quais depositava em vidros de conserva e enterrava junto com roupas e alimentos que subtraía da casa. De uma feita cobrou diversos cheques em moedas de prata de meio dólar e, pondo-as em vidros, enterrou-as no pátio. Perguntada sôbre êste fato, disse saber que o papel-moeda iria perder o valor. A partir de 1946, sua memória para fatos recentes declinou muito. No inverno de 1952-1953, recusou-se a fazer as refeições na mesma mesa com o marido. Foi contratada uma criada para cozinhar e limpar a casa e com ela a doente passou a ter desentendimentos diários, chegando ao extremo de ameaçá-la de morte em fevereiro de 1955. Sua memória continuava a diminuir sensivelmente. A enfêrma tornara-se mais agitada, agressiva, incontínente de fezes e urina, incapaz de vestir-se e despreocupada inteiramente com sua aparência. Um ano mais tarde estava ainda maìs combativa, não dormia à noite; perambulava fora de casa quando não era vigiada, saindo ả rua em trajes menores ou inteiramente despida. Seus hábitos em relação à evacuação de fezes e urina não haviam mudado e ela se dedicava a brincar com seus excretos quando não era observada. Recusava deitar-se alegando ser sua cama um lugar "feio e sujo". Tinha que ser alimentada às colheradas e perdera muito pêso. Quando levada ao vaso sanitário, recusava sentar-se por ser o assento de côr prêta. Por semelhante razão recusava comer alimentos de côr escura, repetindo sempre que eram "feios e sujos". Após anos de insisténcia, o marido e a filha concordaram com o médico da familia e resolveram interná-la em agôsto de 1956.

$\mathrm{Na}$ ocasião de sua entrada no hospital, apresentava-se emagrecida, completamente desorientada em relação ao tempo, pessoas e lugares. Sua atençāo era difícil de se fixar e ainda mais para se manter. Parecia estar confusa e amedrontada. A memória para fatos recentes e remotos estava inteiramente comprometida. Havia dificuldade em entender sua conversação, por vêzes totalmente incoerente e com frequientes explosões de riso e alacridade. Durante as entrevistas, recusava sentar na cadeira, preferindo tocar com as mãos nas paredes da sala ou na barra do vestido. Expunha seus órgãos genitals e, por vêzes, fazia gestos masturbatórios. Adotava atitude sedutora com o examinador, tomando-lhe as mãos e acariciando-lhe os joelhos, enquanto dizia: "Gosto muito de você". Na enfermaria, era um problema conservá-la alimentada e limpa. Continuava a defecar e urinar em qualquer lugar, bricando com os excretos, passando-os nas vestes, no chão e nas paredes.

Foi feito o diagnóstico de "sindrome cerebral crônica secundária à arteriosclerose cerebral com reação psicótica".

$\mathrm{Na}$ conferência diagnóstica e terapêutica recomendou-se a continuação da hospitalização. O médico e a enfermeira-chefe passaram a vê-la diàriamente por breves minutos, numa tentativa de estabelecer relaçōes com ela. A medida que os dias passavam, ficou claro que se comunicava melhor e ficava mais à vontade com a enfermeira, assumindo esta o papel principal em seu tratamento. A todos os atendentes, enfermeiras e terapistas, foi recomendado que usassem uma atitude amigável e solícita para com a doente, recompensando-a com gestos e palavras por qual esfôrço que fizesse. Foram iniciadas pequenas doses de clorpromazina que foram depois aumentadas até $50 \mathrm{mg} 4$ vêzes ao dia. A doente começou a freqüentar, diàriamente, a sala de praxiterapia. Seu primeiro trabalho foi pinturas a dedo. A terapista entregava-lhe fôlhas de papel com um pouco de tinta que ela podia esfregar com os dedos. Mais tarde, começou a servir-se de tinta das bisnagas e logo depois, a trabalhar argila mole, sovando-a durante muito tempo, sem tentar fazer nada, além do simples contato com o material. Junto com outros enfermos, semelhantes a ela, trabalhou com martelo, malhando discos de fôlha para fazer cinzeiros. Além destas atividades, concorria a tôdas as demais da en- 
fermaria. Assistia quieta e contrita às cerimônias religiosas, demonstrando grande prazer em cantar com as outras pacientes. Fêz relação afetiva intensa com o capelão, sendo mais tarde capaz de assistir às suas preleçōes sôbre assuntos bíbilicos.

Após duas semanas, por instância da enfermeira-chefe, utilizava esporàdicamente - vaso sanitário. Seu progresso era lento e marcado por recaídas. Uma gripe forte deu à enfermagem a oportunidade de redobrar os cuidados com a paciente, que saiu desta doença mais lúcida e em melhor contato com a realidade. Aos poucos, começou a dominar a topografia da enfermaria, sendo então capaz de dirigir-se sózinha à sala de praxiterapia, ao refeitório e à sala de enfermagem para receber seus medicamentos. Passados 3 meses, começou a freqüentar sessōes de psicoterapia de grupo, sendo a observadora do mesmo a enfermeira-chefe a quem a doente se afeiçoara e o terapista um médico estranho à enfermaria. No grupo, sua atuação era limitada, ouvindo com atenção, ou simplesmente ficando abstraída. Estêve no grupo durante 18 semanas ( 36 sessōes) e chegou ao ponto de poder manifestar temor em relação ao regresso para sua cidade natal, em vista da alta, então iminente. O ganho mais importante no grupo foi seu progresso em socializar com - terapista, a observadora e as outras doentes no grupo. Isso teve como conseqüéncia um aumento de auto-estima e melhor orientação dentro da realidade.

A doente estêve hospitalizada durante 6 meses e 17 dias. Por ocasião da alta, para regressar e viver com o marido e a filha, estava em contato com a realidade, em condições de cuidar de si e de suas necessidades fisiológicas e de conviver com os parentes. Sua memória continuava falha. A angústia desaparecera em grande parte, embora temesse continuamente sair de casa, pois tinha mêdo de não encontrar o caminho de regresso. Em casa, continuou a tomar clorpromazina (75 mg diários).

\section{COMEN'TARIOS}

Os problemas psiquiátricos da velhice oferecem características especiais e necessitam ser compreendidos através da análise da história do indivíduo (longitudinal) e de seus problemas presentes (transversal) ${ }^{3}$. Além dos stress comuns a tôdas as pessoas, o velho tem os problemas próprios de seu grupo, dentro os quais se deve destacar: a decadência física e psicológica, a dissoIução dos laços familiares e profissionais e, por sua freqüência, as injúrias cerebrais secundárias às dificuldades circulatórias ${ }^{7}, 14$.

As alterações de conduta devem ser compreendidas à luz da psicodinâmica do individuo. O tratamento decorre dessa compreensão e leva em consideração a integridade do ego, as necessidades instintivas em jôgo, as exigências da realidade externa, o tipo de mecanismos de defesa utilizados e o grau de desintegração das funções intelectuais e físicas do doente.

RESUMO

Foi apresentado um resumo das idéias comumente aceitas em psiquiatria dinâmica com relação aos problemas emocionais da velhice. A necessidade de uma solução eclética para esta questão de crescente importância na sociedade hodierna não impede que se utilize, com vantagem, uma orientação psicanantica no tratamento dêsses individuos. No caso apresentado acham-se ilustrados alguns pontos de vista do autor. 


\section{SUMMARY \\ Psychiatric problems of the aging and the aged.}

The emotional problems of the aging and the aged are increasing as the population grows older. To understand and treat these patients the physician has to know the premorbid personality, the past and present history and the precipitating factors responsible for the psychotic or neurotic reaction. The most frequent stresses to this group are: the physical and psychological impairment, the death of close relatives, the retirement problems and the cerebral injuries due to circulatory handicaps.

The effect of those stresses upon the conduct of the patient have to be understood at the light of the psychodynamics of the individual. The treatment is a consequence of this understanding and takes into consideration ego strength, instinctual and reality demands, types of mechanisms of defence utilized and degree of desintegration and impairment of the intelectual and physical functions.

The use of an eclectic approach with psychoanalytic orientation has proved to be the most fruitful way to treat this group of psychiatric patients.

\section{REFERENCIAS}

1. BUSSE, E. W.; BARNES, R. H. e outros - Studies of the process of aging. Am. J. Psychiat., 111:896, 1955. 2. BUTLER, R. N.; PERLIN, S. - Depressive reactions in the aged. $1^{\circ} 3^{\circ}$ Congresso da American Psychiatric Association, Chicago, 1957. 3. DIETHELM, O.; ROCKWELL, F. V. - Psychopathology of aging. Am. J. Psychiat., 99:553, 1943. 4. DOWNING, J.; GRUENBERG, E. M. - The prevalence of mental symptoms in an aged population. $113^{\circ}$ Congresso da American Psychiatric Association, Chicago, 1957. 5. EAST, W. N. - Crime, senescence and senility. J. Ment. Sc., 90:835, 1944. 6. EBAUGH, F. G. - Age introduces stress into the family. Geriatries, 11:146, 1956. 7. GITELSON, M. - Emotional problems of elderly people. Geriatrics, 3:135, 1948. 8. KOLB, L. - Mental hospitalization of the aged: is it being overdone? Am. J. Psychiat., 112:627, 1956. 9. KUBIE, S. H.; LANDAU, G. Group Work with the Aged. Intern. University Press, Nova York, 1953.10. LANSING, A. I. - Cowdry's Problems of Aging, 3a ed. Williams \& Wilkins, Baltimore, 1952. 11. LAWTON, G. - Aging Successfully. Columbia Univ. Press, Nova York, 1946. 12. LINDEN, M. E. - The prevention of mental disturbance in the aging. $114^{\circ}$ Congresso da American Psychiatric Association, São Francisco, 1958. 13. McFARLAND, R. A. - The psychological aspects of aging. Bull. New York Acad. Med., 52:14, 1956. 14. MOORE, J. E.; MERRITT, H. H.; MASSELINK, R. J. - The neurologic and psychiatric aspects of the disorder of aging. Proc. A.R.N.M.D., vol. XXXV. Williams \& Wilkins, Baltimore, 1956. 15. SIMMONS, L. W. - Role of the aged in primitive society. Yale Univ. Press, New Haven, 1945. 16. STIEGLITZ, E. J. - The Second Forty Years. Lippincott Co, Filadélfia, 1946. 17. STrEGLITZ, E. J. - Geriatric Medicine, 2a ed. Saunders Co., Filadélfia, 1949. 18. STIEGLITZ, E. J. - The aging process. Conferencia no Third Mental Hospital Institute, Louisville, 1951. 19. WILLIAMS, A. M. - Recreation for the Aging. Association Press, Nova York, 1953. 20. WILSON, D. C. - The pathology of senility. Am. J. Psychiat., 111:902, 1955. 